\title{
Lead Detoxification of the Childrens' Body by Means of Physical Culture
}

\author{
Medvedkova N. I. \\ University of management "TISBI" \\ Naberezhnye Chelny, Russia \\ medvedkovani@yandex.ru
}

\author{
Kiyamova N.I. \\ University of management "TISBI" \\ Naberezhnye Chelny, Russia \\ nadira.kiamova@yandex.ru
}

\author{
Medvedkov V.D. \\ Gzhel State University \\ Gzhel, Russia \\ medvedkovani@yandex.ru
}

\begin{abstract}
The harmful influence of the environment on health is known. Millions of tons of chemical compounds are released into the environment every year. In the soil when planting various plants, a huge amount of mineral fertilizers, as well as poisonous substances to fight weeds are introduced. Harmful substances enter the body with air, water and food. Air pollution has a harmful effect on humans, especially on the lungs, which serve as a filter to protect the body from airborne toxicants and poisons. With a large concentration of harmful substances in humans, poisoning is observed. With severe poisoning, the overall morbidity increases, as well as the respiratory system. The study involved children from one of the ecologically disadvantaged regions of the Russian Federation with health disorders-60 girls and 90 boys. The paper uses such research methods as analysis and synthesis of literary sources, atomic absorption analysis, pedagogical experiment, anthropometry, spirometry, analysis of documentary sources, methods of mathematical statistics, etc.

The results of the research showed that children living in environmentally unfavorable places have reduced indicators of physical health and functional status: heart rate, lung capacity; breath retention on inhalation and exhalation. The concentration of lead in the body of children is increased several times.

Directed physical activity, used in an environmentally relatively clean place, contribute to the excretion of lead from the body of children. The correlation between the number of trips in insulated clothing and a decrease in the content of lead in the hair of children was revealed: the correlation coefficient is 0.81 in girls, 0.92 in boys.

For unloading of solid biological means of children organism from lead the most rational are occupations in the pool in a complex with thermal air influences (for girls) and land loadings in the warmed clothes in a combination with thermal air (for boys).
\end{abstract}

Keywords-lead; preschool children; physical activity; hiking; swimming; thermal air loads.

\section{INTRODUCTION}

The negative impact of the environment on health is known. Millions of tons of chemical compounds are released into the environment every year. In the soil when planting various plants, a huge amount of mineral fertilizers, as well as poisonous substances to fight weeds are introduced. Harmful substances enter the body with air, water and food. Most of all from polluted air suffer residents of large cities, which have to breathe the exhaust gases of cars. They account for more than half of all harmful emissions.

Air pollution has a harmful effect on humans. With a large concentration of harmful substances in humans, poisoning is observed. With severe poisoning, the overall morbidity increases, as well as the respiratory system. Diseases of the cardiovascular system become more severe. In addition to air, environmentally poor-quality food and water cause pollution of the body. Agricultural products, which are processed with various chemicals, are especially rich in harmful substances. In addition, people eat fried foods, which are many carcinogens that cause cancer.

Scientists have identified the relationship between human health and the environment [1-12]. Children suffer the most

\section{RESEARCH MethodOLOGY}

The study involved children from one of the ecologically disadvantaged regions of the Russian Federation with health disorders-60 girls and 90 boys.

The paper used such research methods as analysis and synthesis of literary sources, atomic absorption analysis, pedagogical experiment, anthropometry, spirometry, analysis of documentary sources, methods of mathematical statistics, etc. Atomic absorption analysis was carried out to determine the concentration of lead in solid (hair) and liquid (urine) biological environments of children. The pedagogical experiment was conducted to determine the effectiveness of lead excretion from the body of preschoolers by various means of physical culture during the sanatorium shift.

For rehabilitation, loads were used in the form of hiking in beautiful natural places, in the form of swimming in the pool and mixed classes, which included Hiking and visiting the sauna with a swimming pool. 
Special physical exercises and elimination massage were used to correct functional disorders of detoxifying organs. To improve the work of the cardiovascular system, cyclic loads were used in the form of trips to beautiful places. For the correction of functional disorders of the lungs were used aerobic exercise, such as swimming in the pool. To improve the work of the hematopoietic system, variable intensity exercise was used with the help of short-term reasonable hypoxia.

The research materials were subjected to mathematical and statistical processing. The following statistical characteristics were calculated: arithmetic means (M), standard error of arithmetic means (m), means square deviation (), coefficient of variation (V), correlation coefficient (r).

\section{RESULTS}

The results of the study showed that children from ecologically disadvantaged areas at the beginning of the study had an inflated heart rate, which indicated an uneconomical cardiovascular system. Vital capacity of both sexes children lungs was below age norm that testified to insufficient functional possibilities of respiratory system. Breath retention on inhalation and exhalation was below the age norm by $30 \%$, indicating low oxygen reserves in the body and reduced resistance of children to hypoxia.

The hemoglobin content in the blood of children was below the corresponding polo-age norm, which indicated a reduced respiratory function of the blood. The number of red blood cells in the blood of children was also below normal, which indicated a deteriorated blood transport function. The reduced content of these two blood parameters indicated a predisposition to anemia.

The number of white blood cells in the blood of children was below the age norm, which indicated a deterioration of the body's defense against various diseases. The rate of erythrocyte sedimentation in children of both sexes was below the age norm.

The lead content in solid biological media of children exceeded the norm by 13-14 times, in liquid-almost 2 times.

For 28-35 days of sanatorium change there were the following shifts. The girls of the control group, ozdoravlivayuschim the plan of the sanatorium with a little physical activity, lead content in hair is significantly decreased from 9 to $6 \mathrm{mcg} / \mathrm{g}$; the girls of the experimental group visited 10 trips, it is unreliable decreased from 3.8 to $2.5 \mu \mathrm{g} / \mathrm{g}$, visited 15 campaigns - significantly from 14.6 to $1.1 \mu \mathrm{g} / \mathrm{g}$.

In boys of the control group, recovering according to the plan of the sanatorium, the lead content in solid biological media significantly decreased by $31.0 \%$. In the boys of the experimental groups there was a decrease in the concentration of lead in the hair: in those who visited 5 hikes - by $76.2 \%$, 10-by $77.8 \%, 15$ hikes-by $96.3 \%$.
Thus, in all experimental groups of children, where increased physical activity in insulated clothing was used during hikes in beautiful terrain, the decrease in the concentration of lead in solid biological media was greater than in the control group. The correlation coefficient between the volume of land trips and the reduction of lead content in the hair of girls is 0.81 , boys- 0.92 .

Consequently, with the increase in the number of trips to beautiful places, the efficiency of lead elimination in solid biological environments of children of both sexes increases.

Thus, the most optimal volume for removing lead from the hair of children is 15 trips per sanatorium shift.

Analysis of the effectiveness of excretion of heavy metals from the body of children depending on the volume of water physical activity (swimming in the pool) showed the following.

During the sanatorium shift, almost all groups of children experienced a decrease in the concentration of lead in solid biological media. In the control group of girls, it significantly decreased by $27.9 \%$. In the experimental group of girls, where each visited for a month 10 bathing, the content of lead in the hair decreased by $31.9 \%$. With 15 bathing per month, the decrease was $72.4 \%$. Consequently, with an increase in the number of bathing in the pool for a sanatorium shift in 28-35 days, the decrease in the concentration of lead in solid biological media increases. The correlation coefficient between the volume of water loads and the reduction of lead content in the hair of girls is 0.81 . Therefore, the rational amount of bathing girls for the removal of lead from solid biological media is 15 per sanatorium shift.

Boys in almost all groups had a similar pattern. In the control group, the decrease in lead concentration was significantly $31 \%$; there was no change for the better in those who visited 5 bathing sessions. The most significant reduction in lead content in hair (54\%) was in the experimental group, where each boy bathed 10 times per sanatorium shift. In boys who bathed 15 times per shift, a significant decrease in the concentration of this toxicant was less $(44.9 \%)$. Thus, in boys, for the removal of lead from solid biological media by physical exertion in the water, it is more rational to take 10 baths, evenly distributed during the sanatorium shift.

In all groups of children during the sanatorium shift there was a decrease in the concentration of lead in the liquid biological media, this indicates the removal of lead from the liquid biological media of children.

In the control group of girls, the concentration of lead in the urine significantly decreased by $2.7 \%$. In the experimental group with 10 classes in the pool, the concentration of lead in the urine of girls decreased by $3.2 \%$, with 15 classes-by $13.3 \%$. This suggests that physical activity in the pool contributed to the removal of lead from the liquid biological media of children. 
In the control group of boys, the lead content in the urine significantly decreased by $21.9 \%$. In the experimental group, where boys attended an average of 10 classes in the pool, the lead content significantly decreased by $40.9 \%$, where they attended 15 classes-by $28.9 \%$.

The change in the concentration of lead in the liquid biological media of children depending on complex loads showed the following. During the sanatorium shift, there was a decrease in the concentration of lead in the urine in children: the girls of the control group significantly decreased by $27.9 \%$. In the experimental group in girls, where 5 complex loads were used-by $75.2 \%$.

In the control group of boys, the lead content in the hair significantly decreased by $31.0 \%$. In the experimental group of boys who attended 5 hikes and 5 impacts in the sauna, it decreased by $37.0 \%, 10$-by $82.3 \%$. The correlation coefficient between the decrease in the concentration of lead in the hair and the volume of complex physical activities is 0.91 .

Sanatorium change is sufficient to normalize the lead content in solid biological media of boys at 10 complex loads.

The change in the concentration of lead in the urine showed the following. In the girls of the control group during the sanatorium shift, the lead content in liquid biological media significantly decreased by $27.5 \%$. In experimental groups at 5 complex loadings-on 5,5\%, at 10 -on $62,9 \%$. Thus, for removal of lead from urine of girls 10 complex physical influences for sanatorium change is the most rational.

In the boys of the experimental group, who attended 5 complex classes during the sanatorium shift, the concentration of lead in the urine decreased by $22.9 \%, 10$ classes-by $66.8 \%$. In the control group, the reduction in lead concentration was $21.9 \%$. The correlation coefficient between these values is 0.87. It follows that for the removal of lead from the urine of boys more rational are 10 complex classes for a sanatorium shift.

\section{CONCLUSION}

1. Children living in ecologically unfavorable places, have reduced indicators of physical health and functional status: heart rate, lung capacity; delay by 2002khaniya on inhalation and exhalation. The concentration of lead in the body of children is increased in liquid and solid biological media up to 15 times.

2. Directed physical activity, used in an environmentally relatively clean place, contribute to the excretion of lead from the body of children. The correlation between the number of trips in insulated clothing and a decrease in the content of lead in the hair of children was revealed: the correlation coefficient is 0.81 in girls, 0.92 in boys.

3. For unloading of solid biological means of an organism of children from lead the most rational are occupations in the pool in a complex with thermal air influences (for girls) and land loadings in the warmed clothes in a combination with thermal air (for boys).

\section{References}

[1] Dautov F.F. Study of population health in connection with environmental factors. Kazan. 1990, pp. 2-15.

[2] Dautov F.F. Prognosis of the level of morbidity of children 3-7 years depending on changes in the degree of pollution of atmospheric air. Hygiene and sanitation. 1990, 3, pp. 2-15.

[3] Dautov F.F., Yarullin I.A. Study of the relationship between environmental pollution and the level of morbidity of children's population of the city. Hygiene and sanitation. 1993, 8, pp. 4-6.

[4] Dimitriev D.A. Studying the influence of atmospheric air pollution on the state of the respiratory system in children. Hygiene and sanitation. 1994, 7, pp. 7-9.

[5] Maimulov V.G., Patsyuk N.A., Baskovich G.A. Hygienic assessment of the impact of chemical pollution of the environment of the metropolis on the health of children. Hygiene and sanitation. 2004, 2, pp. 31.

[6] Savchenko O.V. Influence of environmental pollution by heavy metals on the health of preschool children. human Ecology. 2018, 3, pp. 16-20.

[7] Injuk J., Otten P., Laane R. et al. Atmospheric concentrations and size distributions of aircraft-sampled $\mathrm{Cd}, \mathrm{Cu}, \mathrm{Pb}$ and $\mathrm{Zn}$ over the Southern Bight of the North Sea. Almos.environ. 1992, vol. 26A, 14, pp. 24992509.

[8] Frildman J.A., Weinberger H.F. Six children with lead poisoning. Am. J. Dis.Child. 1990, vol. 144, 3, pp. 1039-1044.

[9] Alegria A., Barbera R., Farre R. Influence of environmental contamination on $\mathrm{Cd}, \mathrm{Co}, \mathrm{Cr}, \mathrm{Ni}, \mathrm{Pb}$ and $\mathrm{Zn}$ content of edible vegetables: Safety and nutritional aspects. J. Micronuts. anal. 1990, vol. 8, 2, pp. 91104.

[10]Julian J. Pediatric exposures to lead, arsenic, cadmiam and methyl mercury. Nestle Nutrition. 1986, pp. 19-23.

[11]Bhattacherya A., Shubla R., Bornischein R.L., et al. Lead effects on postural of children. Environ. health perspect. 1990, vol. 89, pp. 35-42.

[12] Alexsandr S. Kuznetsov. Russian Professor's meeting. Russian Journal of Physical Education and Sport. 2019, 14(1), pp. 17-22. DOI: 10.14526/2070-4798-2019-14-1-18-24

[13]Revich B. Elements in the children hair as an indicator of air pollution in cities. Abstract Seventh international sympozium on trace elements in manual animals. Jugoslavia. 1994, pp. 147. 